\title{
Large-Scale Gene Discovery in the Septoria Tritici Blotch Fungus Mycosphaerella graminicola with a Focus on In Planta Expression
}

\author{
Gert H. J. Kema, ${ }^{1}$ Theo A. J. van der Lee, ${ }^{1}$ Odette Mendes, ${ }^{1}$ Els C. P. Verstappen, ${ }^{1}$ René Klein Lankhorst, ${ }^{2}$ \\ Hans Sandbrink, ${ }^{2}$ Ate van der Burgt, ${ }^{1}$ Lute-Harm Zwiers, ${ }^{3}$ Michael Csukai, ${ }^{4}$ and Cees Waalwijk ${ }^{1}$ \\ ${ }^{1}$ Plant Research International B.V., P.O. Box 16, 6700 AA Wageningen, The Netherlands; ${ }^{2}$ Greenomics, Plant Research \\ International B.V., P.O. Box 16, 6700 AA Wageningen, The Netherlands; ${ }^{3}$ Laboratory of Phytopathology, Wageningen \\ University, 6709 PD Wageningen, The Netherlands; ${ }^{4}$ Syngenta, Jealott's Hill International Research Centre, Bracknell, \\ Berkshire, U.K.
}

Submitted 19 November 2007. Accepted 30 April 2008.

The foliar disease septoria tritici blotch, caused by the fungus Mycosphaerella graminicola, is currently the most important wheat disease in Europe. Gene expression was examined under highly different conditions, using 10 expressed sequence tag libraries generated from $M$. graminicola isolate IPO323 using seven in vitro and three in planta growth conditions. To identify fungal clones in the interaction libraries, we developed a selection method based on hybridization with the entire genomic DNA of $M$. graminicola, to selectively enrich these libraries for fungal genes. Assembly of the 27,007 expressed sequence tags resulted in 9,190 unigenes, representing 5.2 $\mathrm{Mb}$ of the estimated 39Mb genome size of $M$. graminicola. All libraries contributed significantly to the number of unigenes, especially the in planta libraries representing different stages of pathogenesis, which covered $15 \%$ of the library-specific unigenes. Even under presymptomatic conditions (5 days postinoculation), when fungal biomass is less than $5 \%$, this method enabled us to efficiently capture fungal genes expressed during pathogenesis. Many of these genes were uniquely expressed in planta, indicating that in planta gene expression significantly differed from in vitro expression. Examples of gene discovery included a number of cell walldegrading enzymes, a broad set of genes involved in signal transduction $(n=11)$ and a range of ATP-binding cassette $(n=20)$ and major facilitator superfamily transporter genes $(n=12)$ potentially involved in protection against antifungal compounds or the secretion of pathogenicity factors. In addition, evidence is provided for a mycovirus in $M$. graminicola that is highly expressed under various stress conditions, in particular, under nitrogen starvation. Our analyses

H. Sandbrink passed away on May 10, 2002.

Current address of L.-H. Zwiers: KNAW-Fungal Diversity Center, P.O. Box 85167, 3508 AD Utrecht, The Netherlands.

Corresponding author: Gert H. J. Kema, Telephone +31.317.476149; Fax +31.317.418094; E-mail: gert.kema@wur.nl

Nucleotide sequence data of the Mycosphaerella graminicola expressed sequence tags are available in the EMBL database. M. graminicola IPO323 is available from our group at Plant Research International as well as at the KNAW-Fungal Diversity Center. provide a unique window on in vitro and in planta gene expression of M. graminicola.

Septoria tritici blotch is caused by Mycosphaerella graminicola (Fuckel) J. Schröt. in Cohn. The genus Mycosphaerella is probably the largest genus of plant pathogens in the fungal kingdom, representing at least 3,000 species on a wide array of crops, including cereals, banana, citrus, soybeans, sugar beets, tomatoes, strawberries, and tree crops (Farr et al. 1995). Septoria tritici blotch has regularly been a significant threat to wheat production over at least 160 years in the U.K. (Bearchell et al. 2005) and, particularly during the last decade, all over Western Europe.

Despite the recent identification of 15 resistance genes and their potential application in breeding (Goodwin 2007), disease control is currently achieved mainly by fungicides. However, only azoles and strobilurines are available, and reduced efficacy to field populations is a constant threat to sustainable wheat production. This was recently underscored by the development of resistance in $M$. graminicola against strobilurines and its rapid spread across Europe (Sierotzki et al. 2005). Together with decreasing efficacy of particular azoles (Fraaije et al. 2007), the need for new targets for disease control is evident.

Due to its experimental amenability and economic significance, $M$. graminicola is rapidly developing as a model, not only for the family Mycosphaerellaceae but also for the order of the Dothideales (Goodwin et al. 2004; Kema et al. 2000, 2002; Mehrabi and Kema 2006; Mehrabi et al. 2006a and b). In contrast to some other plant-pathogenic model fungi such as Magnaporthe oryzae (Dean et al. 2005), M. graminicola does not produce appressoria to actively penetrate host cells. $M$. graminicola is a dimorphic fungus that proliferates through blastic conidiogenesis under rich conditions, while growth is filamentous under nutrient-poor conditions and on leaf tissue. Infection commences by hyphae entering through stomates without differentiating infection structures (Kema et al. 1996; Mehrabi et al. 2006b). Subsequent development is biotrophic, intercellular, and symptomless for at least 10 days. The following rapid necrotrophic process, involving cell-wall degradation and a potential active role of toxic compounds and hydrogen peroxide in pathogenesis, results in massive collapse of mesophyll tissue, rapid increase of fungal biomass, and formation 
of fructifications in characteristic necrotic foliar blotches (Duncan and Howard 2000; Kema et al. 1996; Shetty et al. 2007). These fructifications contain either sexual spores that are airborne or asexual spores that are dispersed by rain splash.

Table 1. Expressed sequence tag (EST) libraries made from Mycosphaerella graminicola IPO323

\begin{tabular}{llcc}
\hline Library & \multicolumn{1}{c}{ Condition $^{\mathbf{a}}$} & Duration & Starting culture $^{\mathbf{b}}$ \\
\hline EST1 & Plant apoplast, $16^{\circ} \mathrm{C}$ & $73 \mathrm{~h}$ & YGB \\
EST2 & YGB, $16^{\circ} \mathrm{C}$ & $100 \mathrm{~h}$ & YGB \\
EST3 & YGB, $25^{\circ} \mathrm{C}$ & $100 \mathrm{~h}$ & YGB \\
EST4 & MM broth $+\mathrm{N}, 16^{\circ} \mathrm{C}$ & $60 \mathrm{~h}$ & MM \\
EST5 & MM broth $-\mathrm{N}, 16^{\circ} \mathrm{C}$ & $60 \mathrm{~h}$ & MM \\
EST6 & Water agar, room temperature & $36 \mathrm{~h}$ & YGB \\
EST7 & Cyproconazole stress, $25^{\circ} \mathrm{C}$ & $1 \mathrm{~h}$ & YGB \\
EST8 & Infected wheat leaves & $5 \mathrm{dpi}^{\mathrm{c}}$ & YGB \\
EST9 & Infected wheat leaves & $10 \mathrm{dpi}$ & YGB \\
EST10 & Infected wheat leaves & $16 \mathrm{dpi}$ & YGB \\
\hline
\end{tabular}

${ }^{\mathrm{a}}$ The in planta conditions were similar to those described by Kema and Van Silfhout (1997)

${ }^{\mathrm{b}} \mathrm{YGB}=$ yeast glucose broth; $\mathrm{MM}=$ minimal medium.

${ }^{\mathrm{c}} \mathrm{dpi}=$ days postinoculation
The continuous production of sexual spores, their higher infection efficiency, and long-range migration probably account for the complex genetic structure of natural populations (Zhan et al. 2003).

The aim of this study was to obtain a large and diverse set of genes of M. graminicola in order to identify genes that are crucial for disease development and that are specifically expressed during the host-pathogen interaction. We generated 9,190 unigenes from three in planta and seven in vitro cDNA libraries that were assembled to unigenes that were analyzed based on homology, functional category, pathway, and expression profile.

\section{RESULTS}

Growth and morphology of $M$. graminicola under different in planta and in vitro experimental conditions used for expressed sequence tag (EST) generation.

The conditions used to generate the EST libraries were chosen to display both the dimorphic and pathogenic lifestyles of $M$. graminicola in order to capture the widest possible gene expression (Table 1; Fig. 1). In apoplastic fluids extracted from
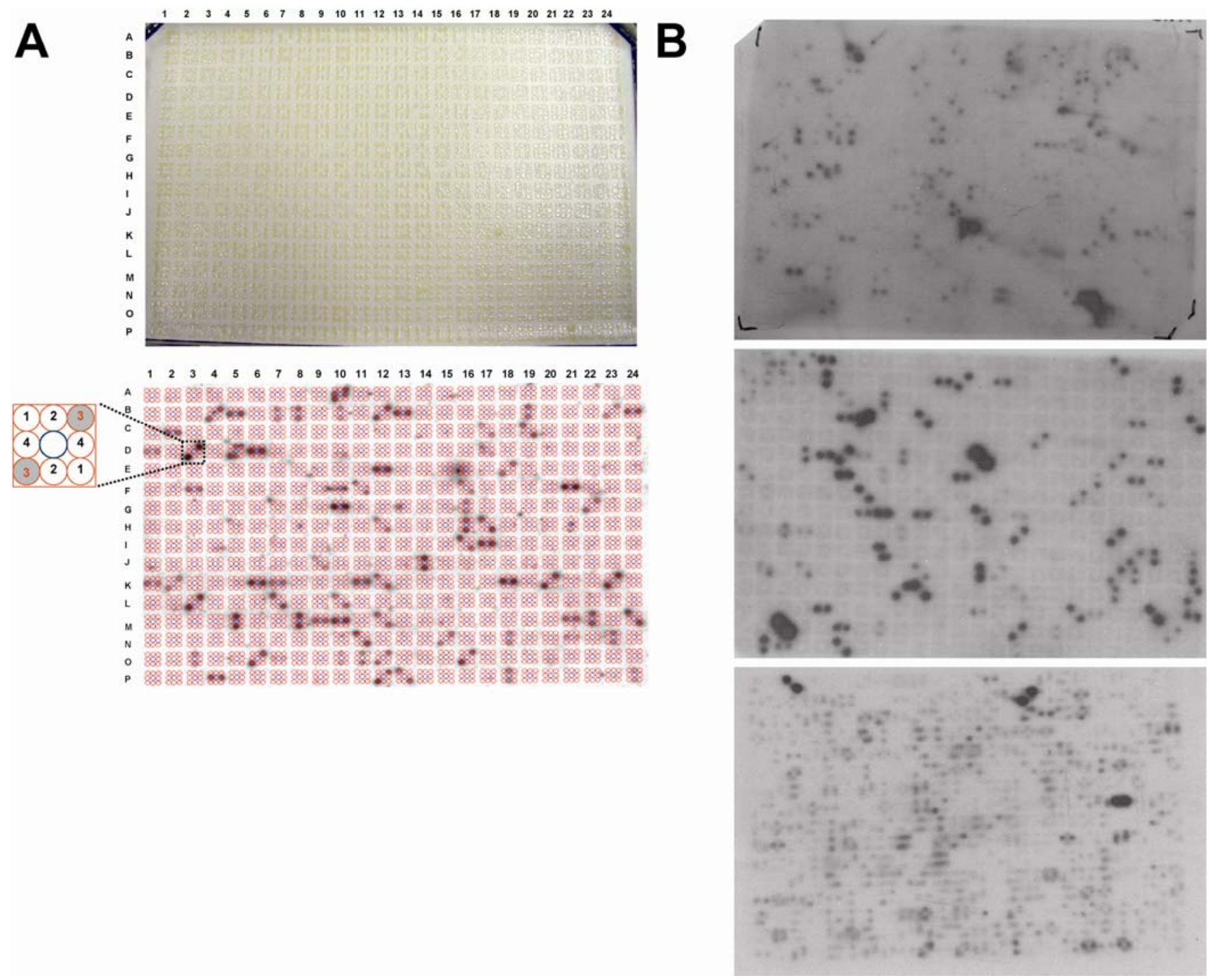

Fig. 1. Identification and selection of fungal clones from the Mycosphaerella graminicola in planta libraries EST8 through EST10. A, Clones $(n=3,072 ;$ i.e., $384 \times 4$ plates $\times 2$ duplicates) were spotted on high density membranes (upper panel) and were subsequently hybridized with total genomic DNA from isolate IPO323 (lower panel). Software was developed to overlay the filters and to evaluate the density of the spots, which were averaged per filter, and thresholds were calculated to select spots that had a significantly higher density than the background. B, Representative high density filters of EST8 (top panel), EST9 (middle panel), and EST10 (lower panel). Note the increasing number of hybridizing clones, indicating the increasing ratio of fungal to plantexpressed genes over a timecourse of 5 to 16 days after inoculation. 
wheat leaves supplemented with a kitchen sponge (EST1), filamentous growth was observed, mimicking the intercellular development of $M$. graminicola in the wheat mesophyll (Kema et al. 1996). Growth in yeast glucose broth (YGB) resulted in the typical blastic conidiogenesis at $16^{\circ} \mathrm{C}$ that merely generates multicelled conidia, while at $25^{\circ} \mathrm{C}$ a fungal matrix of intertwined melanized hyphae was obtained (EST2 and EST3, respectively). Two minimal media, with (EST4) or without (EST5) $\mathrm{KNO}_{3}$ as sole nitrogen source, represent growth under nutrient limitation and significantly reduced growth and spore production. Filamentous growth of germinating conidiospores on water agar at $20^{\circ} \mathrm{C}$ (EST6) morphologically resembles the development on a wheat leaf surface (Mehrabi et al. 2006b). The culture that we used for the production of EST7 showed filamentous growth, which is similar to the physiological state of the fungus upon plant infection. The plants that were used to produce the in planta EST8 to EST10 showed the typical disease development at the three sampling stages (Kema et al. 1996).

\section{EST library quality control.}

The quality of the EST libraries was evaluated at three levels. First, the average insert size of the in vitro libraries ranged from $1.5 \mathrm{~kb}$ for EST5 (nitrogen starvation) to $1.9 \mathrm{~kb}$ for EST2 (yeastlike growth), which agrees well with the average gene length of other ascomycetes like Neurospora crassa (Galagan et al. 2003) or Magnaporthe oryzae (Dean et al. 2005). Secondly, BLAST analyses on a subset of 96 reads from EST3 (mycelial growth) identified 26 strong hits (E-value $<-10)$ to well-characterized genes. In 18 of these, a putative translation start codon could be identified (or sufficient sequence at the $5^{\prime}$ end of the alignment was present to accommodate a translation start), indicating that $70 \%$ of these EST clones are full-length. Thirdly, the elongation factor $1 \alpha(E F-1 \alpha)$ gene was abundantly expressed in all libraries and was used to estimate the percentage of full-length clones present in the different EST libraries. Reads corresponding to $E F-1 \alpha$, which encodes a predicted transcript of 1,566 nucleotides (nt), were sequenced 221 times and we identified the start codon in 158 reads, indicating that $70 \%$ of these sequenced clones were full-length. A similar analysis on 56 sequences of $E F-2$, which encodes a predicted transcript of 2,374 nt, found $37 \%$ full-length clones, indicating that the percentage of fulllength clones decreased with increasing transcript length.

Selection of fungal genes from the interaction libraries.

In EST8, we screened 12,288 EST clones and selected 614 (5\%), based on the hybridization with the labeled M. graminicola genomic DNA. In EST9, 21,504 clones were screened, of which 2,016 (9\%) were selected. Finally, in EST10, we screened 9,216 clones, of which 2,764 (30\%) showed positive hybridization with the $M$. graminicola genomic DNA. This observation corresponds well with the initial (5 days postinoculation [dpi]) very low and later (after $10 \mathrm{dpi}$ ) increasing fungal biomass (Fig. 1; Kema et al. 1996). Analysis by BLASTX against the GenBank nonredundant database resulted in best hits with genes of fungal origin $($ E-value $<-10)$. In addition, some of the sequences had a high number of hits with animal or bacterial sequences, or both. Only 3 to $5 \%$ of the genes had their highest number of hits with genes from plant origin, indicating that $>90 \%$ of the sequenced clones in EST8, EST9, and EST10 were likely of fungal origin, showing the successful selection for fungal genes in these libraries (Fig. 2), which was confirmed by BLAST analyses to the M. graminicola IPO323 genome sequence.

DNA sequencing, assembly, and diversity.

A total of 27,007 reads were generated, resulting in 9,190 contigs yielding a unigene for every 2.94 reads. These 9,190 unigenes represented 6,013 genes that were solely expressed in one library and an additional set of 3,177 genes that occurred in two or more libraries. The average read length was $460 \mathrm{bp}$ and average contig length $576 \mathrm{bp}$.

The average number of reads per contig varied between libraries from 1.16 in library EST8 to 2.45 in library EST6. However, based on the numbers of library-specific unigenes,

Table 2. Statistics for Mycosphaerella graminicola expressed sequence (EST) libraries EST1 to EST10

\begin{tabular}{|c|c|c|c|c|c|c|c|c|c|c|c|}
\hline \multirow[b]{2}{*}{ Number of } & \multicolumn{7}{|c|}{ In vitro libraries } & \multicolumn{3}{|c|}{ In planta libraries } & \multirow[b]{2}{*}{ Total } \\
\hline & EST1 & EST2 & EST3 & EST4 & EST5 & EST6 & EST7 & EST8 & EST9 & EST10 & \\
\hline Reads & 855 & 4,219 & 2,794 & 3,758 & 4,152 & 3,270 & 4,269 & 515 & 1,412 & 1,763 & 27,007 \\
\hline Contigs & 610 & 2,596 & 1,706 & 2,136 & 2,611 & 1,744 & 1,740 & 444 & 1,016 & 1,282 & 9,190 \\
\hline Reads/contigs & 1.40 & 1.63 & 1.64 & 1.76 & 1.59 & 1.88 & 2.45 & 1.16 & 1.39 & 1.38 & 2.94 \\
\hline $\begin{array}{l}\text { Library-specific unigenes } \\
(\%)\end{array}$ & $\begin{array}{l}171 \\
(28)\end{array}$ & $\begin{array}{l}1,070 \\
(41)\end{array}$ & $\begin{array}{l}653 \\
(38)\end{array}$ & $\begin{array}{l}703 \\
(33)\end{array}$ & $\begin{array}{l}1,128 \\
(43)\end{array}$ & $\begin{array}{l}795 \\
(46)\end{array}$ & $\begin{array}{l}561 \\
(32)\end{array}$ & $\begin{array}{l}154 \\
(35)\end{array}$ & $\begin{array}{l}326 \\
(32)\end{array}$ & $\begin{array}{l}452 \\
(35)\end{array}$ & $\begin{array}{l}6,013 \\
(65)\end{array}$ \\
\hline Total contig length & & & & & & & & & & & $5.2 \mathrm{Mb}$ \\
\hline
\end{tabular}
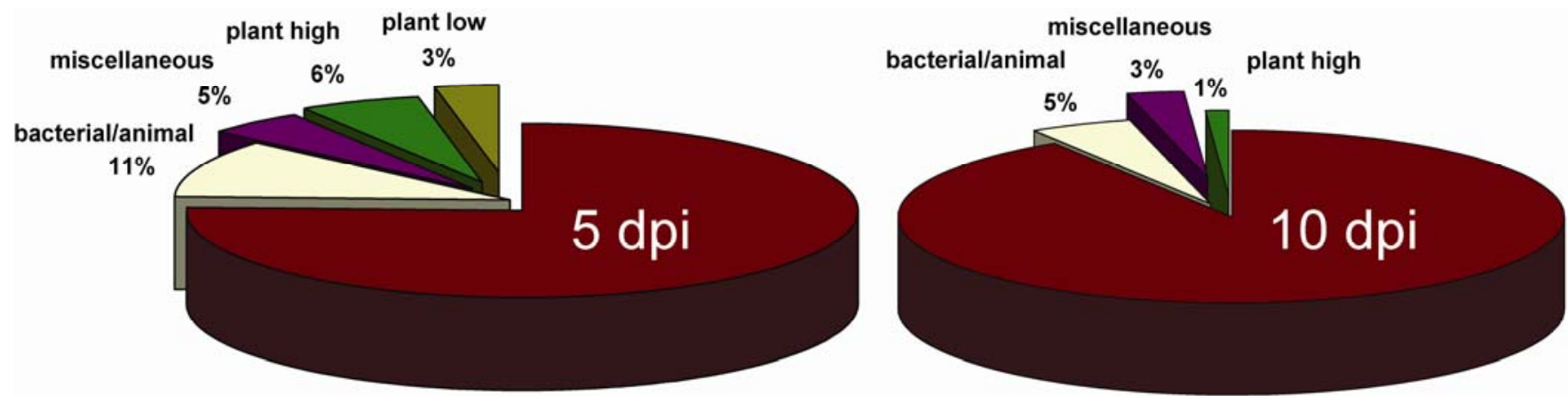

Fig. 2. Efficient enrichment for fungal genes in Mycosphaerella graminicola in planta expressed sequence tag libraries ETS8 (5 dpi) and EST9 (10 dpi) by hybridization of high-density filters with total genomic DNA of isolate IPO323. The number of fungal clones significantly increased using this selection method; 75 and $91 \%$ of the sequenced clones in EST8 and EST9, respectively, were of fungal origin based on the high BLAST hits to fungal databases and the $M$. graminicola genome sequence. The remaining clones could not unambiguously be linked to fungal genes and were mostly similar to highly conserved genes among both plant, animal, fungal, or bacterial kingdoms. 
all EST libraries contributed substantially to the overall set of 9,190 unigenes (Table 2). This is illustrated by the high overall percentage $(65 \%)$ of unigenes that occurred in just one of the libraries. Hence, each condition apparently turned on specific gene sets, demonstrating the necessity of applying diverse cultural conditions to obtain a genome-wide coverage (Table 2). Despite the lower number of reads in the in planta libraries $(3,679)$, these EST contributed significantly to the overall number of unigenes, as $15 \%$ of the library-specific unigenes originated from these in planta libraries.

\section{Cluster analysis of the libraries.}

Multiple EST libraries from a single isolate grown under a variety of in vitro and in planta conditions resulted in a great diversity in gene expression (Table 2; Fig. 3). The EST8 to EST10 in planta libraries clustered with EST1 that was derived from growth in apoplastic fluids and EST6, which was prepared from germinating conidia on water agar. EST1 was designed to mimic the early biotrophic phase of pathogenesis, and the clustering of EST1 with the EST8 to EST10 in planta libraries indeed indicated that these conditions apparently switched on similar groups of genes. As indicated above, we observed that germination on water agar morphologically resembles the development on a wheat leaf surface (Mehrabi et al. 2006b) and, hence, may switch on similar gene sets. The cluster analysis corroborates this suggestion, as EST6 clusters along with EST1 and the in planta libraries. Together these five libraries comprised transcripts that were not expressed or were only expressed to a limited extent in the remaining five in vitro libraries. The in planta libraries resulted in the expression of 932 unique genes that were not found in any of the in vitro libraries and, therefore, contributed significantly to the overall set of unigenes. Furthermore, EST7 was distinct from the other libraries (Fig. 3), suggesting that fungicide stress has a marked impact on gene expression, even after $1 \mathrm{~h}$. These differences were qualitative since EST7 contributed relatively few library-specific unigenes (Table 2 ), as well as quantitative, which is indicated by the expression patterns of abundant messengers (Table 3 ).

\section{Functional annotation of unigenes.}

BLASTx analyses to the nonredundant database showed no significant hits for 2,495 of the 9,190 unigenes. BLASTn analyses of the unigenes set to the public $M$. graminicola EST in GenBank (e-10) showed that 7,538 (82\%) had no hit. Clas- sification of the unigenes into functional categories, as defined by the Munich Information Center for Protein Sequences (Mewes et al. 2002), showed that 5,179 unigenes (56\%) had no significant hit (E-value < -5) and, therefore, could not be classified. The remaining 4,011 unigenes were predominantly related to metabolism (30\%), unclassified and not clearly classified proteins (19\%), transcription (10\%), cell fate $(9 \%)$, protein folding, modification, or destination $(7 \%)$, protein synthesis (7\%), and 12 additional categories with percentages $\leq 6 \%$. Comparison of the $M$. graminicola unigenes with those identified in other ascomycetes showed that a significant percentage $(57 \%)$ showed similarity (E-value $<-10)$ to unigenes annotated in the wheat pathogen Stagonospora nodorum, which also belongs to the class Dothideomycetes. Lower percentages of similarity (threshold E-value $<-10$ ) were obtained with more distantly related organisms such as Fusarium graminearum, which also occurs on barley, maize, and rice (51\%), the rice pathogen Magnaporthe oryzae (49\%), and the saprophyte Neurospora crassa (48\%). In contrast, only $27 \%$ of the $M$. graminicola unigenes demonstrated similarity with genes in the budding yeast Saccharomyces cerevisiae (Fig. 4).

\section{Evidence for a mycovirus in M. graminicola.}

The contig representing the most abundantly expressed gene contained 358 reads (Table 3 ) and showed a strong similarity (E-value $<-83$ ) to the carboxy-terminal half of an RNA-dependent RNA polymerase from a double-stranded (ds)RNA mycovirus identified in Fusarium graminearum (Chu et al. 2002). This region contains the helicase domain. No hits were obtained upon BLAST analysis of this unigene to the sequenced genome of $M$. graminicola isolate IPO323. Since the genome sequence is nearly complete, this suggests that, as expected for a virus, the sequence is absent from the genome sequence. Interestingly, the frequency of reads from this gene was highly disproportional between the different growth conditions. Whereas the abundance ranged between 1.4 and $4.1 \%$ under most conditions, expression was highly repressed during mycelial growth at $25^{\circ} \mathrm{C}(0.04 \%)$ or under fungicide stress $(0.19 \%)$. Surprisingly, the in planta libraries contributed three of the 358 reads $(0.8 \%)$ assembled in this contig.

\section{Signal transduction.}

We identified a number of homologs of genes involved in signaling pathways controlling mating, invasive growth, cell-

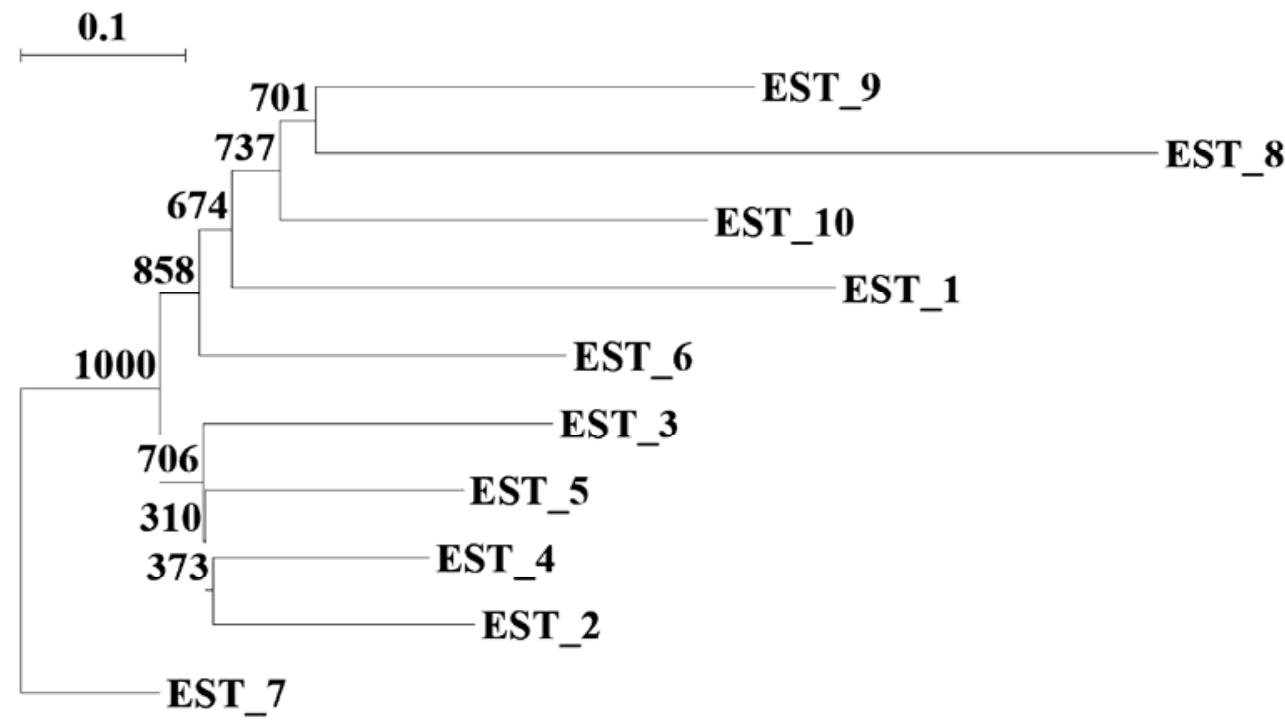

Fig. 3. Cluster analysis of the Mycosphaerella graminicola libraries EST1 through EST10. The tree was rooted using EST7. Numbers at nodes indicate bootstrap support. 
Table 3. The most abundant mRNAs and their putative function based on best hits in the GenBank nonredundant (nr) database using BLASTX

\begin{tabular}{|c|c|c|c|c|c|c|c|c|c|c|c|c|c|c|c|}
\hline \multirow[b]{2}{*}{ Unigene } & \multirow[b]{2}{*}{$E$-value } & \multirow[b]{2}{*}{ Accession no. } & \multirow[b]{2}{*}{ Species } & \multirow[b]{2}{*}{ Function $^{a}$} & \multirow[b]{2}{*}{ Reads $^{b}$} & \multicolumn{7}{|c|}{ In vitro } & \multicolumn{3}{|c|}{ In planta } \\
\hline & & & & & & 1 & 2 & 3 & 4 & 5 & 6 & 7 & 8 & 9 & 10 \\
\hline 5P09K00110 & $1 e-83$ & YP_223920 & Fusarium graminearum & $\begin{array}{l}\text { RNA-dependent RNA } \\
\text { polymerase (dsRNA } \\
\text { mycovirus-1) }\end{array}$ & 358 & 12 & 58 & 1 & 72 & 171 & 33 & 8 & 0 & 2 & 1 \\
\hline 4P10K00214 & 0.0 & XP_001594091 & Sclerotinia sclerotiorum & $\begin{array}{l}\text { Translation elongation } \\
\text { factor EF- } 1 \alpha\end{array}$ & 221 & 4 & 50 & 39 & 44 & 26 & 34 & 4 & 6 & 7 & 7 \\
\hline 3Р07K00345 & $5 e-52$ & XP_001560854 & Botryotinia fuckeliana & $\begin{array}{l}\text { Covalently-linked cell } \\
\text { wall protein }^{c}\end{array}$ & 147 & 3 & 25 & 25 & 22 & 14 & 16 & 21 & 0 & 10 & 11 \\
\hline 7P19K00361 & $3 e-45$ & XP_001541652 & Neurospora crassa & $\begin{array}{l}\text { Conserved hypo- } \\
\text { thetical protein }\end{array}$ & 115 & 0 & 13 & 29 & 21 & 0 & 0 & 52 & 0 & 0 & 0 \\
\hline 9AK001728 & $5 e-37$ & EAT88395 & Phaeosphaeria nodorum & $\begin{array}{l}\text { Hypothetical protein } \\
\text { SNOG_04635 }\end{array}$ & 105 & 1 & 22 & 25 & 9 & 15 & 1 & 9 & 7 & 8 & 8 \\
\hline 4P12K00296 & $8 \mathrm{e}-73$ & XP_001385252 & Pichia stipitis & $\begin{array}{l}\text { Putative glycosyl } \\
\text { hydrolase }\end{array}$ & 95 & 2 & 10 & 17 & 26 & 20 & 2 & 13 & 0 & 2 & 3 \\
\hline 9AK001731 & $1 e-47$ & XP_001243001 & Coccidioides immites & $\begin{array}{l}\text { SCP-like extracellular } \\
\text { protein }\end{array}$ & 88 & 6 & 12 & 4 & 15 & 15 & 8 & 11 & 1 & 8 & 8 \\
\hline 7P21K00152 & $1 e-35$ & XP_714108 & Candida albicans & $\begin{array}{l}\text { Hypothetical protein } \\
\mathrm{CaO} 19.11553\end{array}$ & 85 & 5 & 3 & 3 & 8 & 9 & 7 & 50 & 0 & 0 & 0 \\
\hline 6P12K00012 & $6 e-142$ & EAT77462 & Phaeosphaeria nodorum & $\begin{array}{l}\text { 60S ribosomal protein } \\
\mathrm{P}^{\mathrm{c}}\end{array}$ & 84 & 5 & 9 & 6 & 13 & 3 & 22 & 26 & 0 & 0 & 0 \\
\hline 4P12K00131 & $6 e-78$ & EAT83001 & Phaeosphaeria nodorum & $\begin{array}{l}\text { Hypothetical protein } \\
\text { SNOG_09736 }\end{array}$ & 84 & 3 & 3 & 22 & 16 & 3 & 16 & 20 & 0 & 1 & 0 \\
\hline 4P2K00015 & 0.0 & XP_AF510861 & Emericella nidulans & Acyl-Co $\bar{A}$ desaturase & 77 & 1 & 13 & 19 & 14 & 19 & 6 & 3 & 0 & 2 & 0 \\
\hline 7P17K00284 & 0.0 & XP_00118182 & Chaetomium globosum & $\begin{array}{l}\text { ATP synthase beta } \\
\text { chain, mitochondrial } \\
\text { precursor }\end{array}$ & 77 & 1 & 9 & 5 & 11 & 8 & 5 & 36 & 0 & 1 & 1 \\
\hline 7P19K00215 & 0.0 & AAQ83701 & Trichophyton verrucosum & $\begin{array}{l}\text { 70-kDa heat shock } \\
\text { protein }\end{array}$ & 76 & 11 & 15 & 4 & 17 & 4 & 3 & 13 & 0 & 5 & 4 \\
\hline 10AK00385 & $7 e-107$ & EAT92302 & Phaeosphaeria nodorum & Opsin $\sin ^{\mathrm{c}}$ & 74 & 3 & 8 & 17 & 14 & 11 & 6 & 5 & 1 & 3 & 6 \\
\hline 2P6K00334 & $1 e-20$ & CAC 14775 & Cladosporium fulvum & $\begin{array}{l}\text { Putative transcription } \\
\text { factor }\end{array}$ & 72 & 3 & 33 & 5 & 14 & 8 & 7 & 2 & 0 & 0 & 0 \\
\hline 7P17K00157 & 0.0 & XP_367848 & Magnaporthe grisea & $\begin{array}{l}\text { Mitochondrial F1 } \\
\text { ATPase subunit } \\
\text { alpha }\end{array}$ & 72 & 2 & 8 & 3 & 8 & 7 & 8 & 26 & 0 & 6 & 4 \\
\hline $\begin{array}{l}\text { 9ARRAY01 } \\
\text { K00257 }\end{array}$ & 0.0 & AF464911 & Aspergillus fumigatus & $\begin{array}{l}\text { 60S ribosomal protein } \\
\text { L3 }\end{array}$ & 68 & 1 & 1 & 2 & 7 & 1 & 8 & 44 & 0 & 1 & 3 \\
\hline 7P04K00323 & $4 e-39$ & XP_751076 & Aspergillus fumigatus & WSC domain protein & 68 & 1 & 10 & 4 & 6 & 4 & 5 & 33 & 1 & 1 & 3 \\
\hline 7P10K00094 & $3 e-09$ & XP_001218635 & Aspergillus terreus & Predicted protein & 68 & 3 & 14 & 10 & 4 & 6 & 14 & 4 & 1 & 6 & 6 \\
\hline 7P19K00122 & $1 \mathrm{e}-129$ & EAT92167 & Phaeosphaeria nodorum & Ribosomal protein $\mathrm{S} 2^{\mathrm{c}}$ & 67 & 2 & 3 & 5 & 7 & 1 & 7 & 41 & 0 & 0 & 1 \\
\hline
\end{tabular}

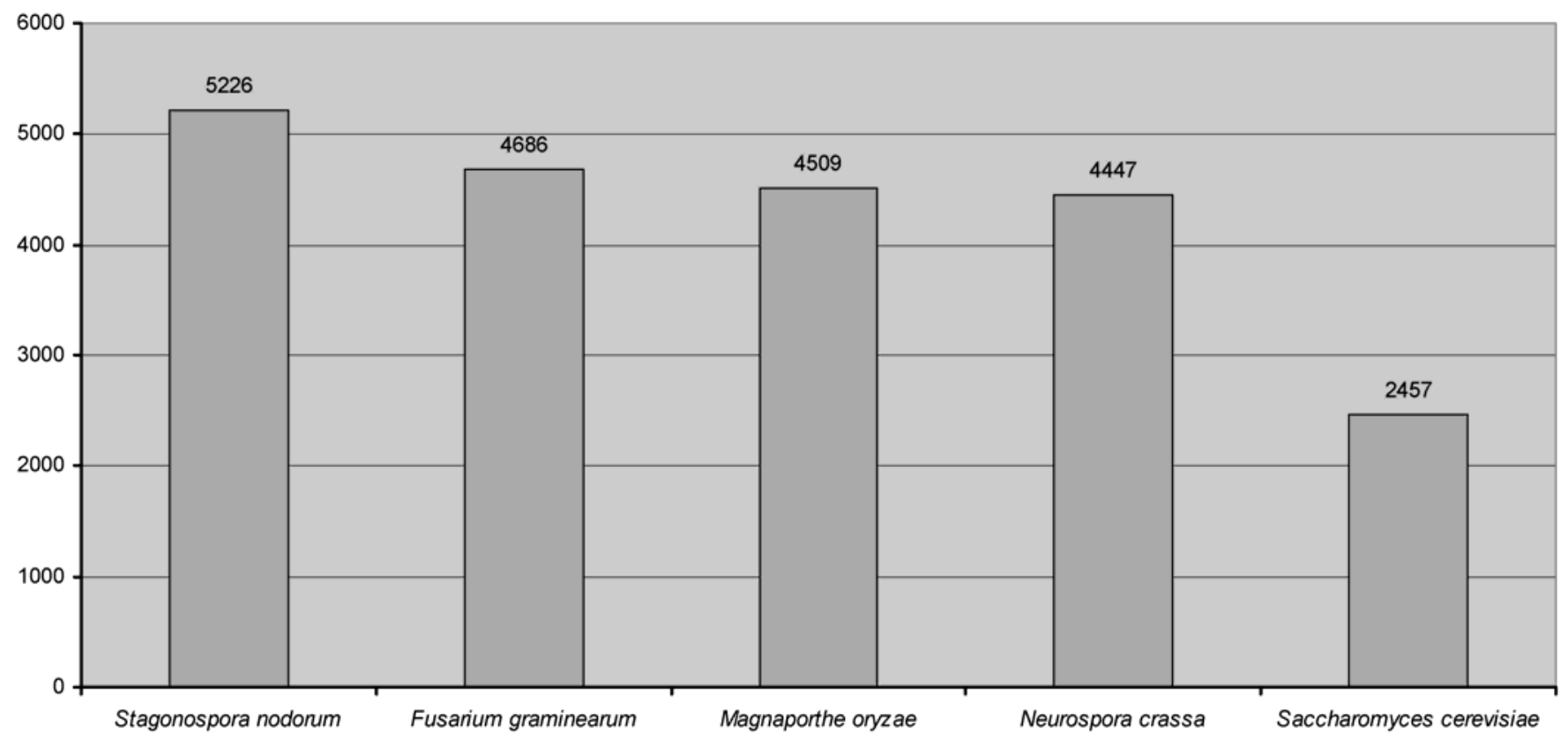

Fig. 4. The number of identified unigenes in Mycosphaerella graminicola, with significant hits (e-10) in the genomes of Stagonospora nodorum, Fusarium graminearum, Magnaporthe oryzae, Neurospora crassa, and Saccharomyces cerevisiae. 
wall integrity, and high osmolarity sensing, as well as genes from the cAMP-dependent pathway. Seventy-four transcripts composed 11 signal transduction genes (Table 4). In N. crassa, these pathways contain three $\mathrm{G} \alpha$ genes, one $\mathrm{G} \beta$ gene, three mitogen-activated protein kinase kinase kinase (MAPKKK), three MAPKK, three MAPK, and two PKA-C genes (Galagan et al. 2003), and for most, we could identify M. graminicola orthologs (Table 4). All these genes were expressed in multiple libraries, except $S s k 2$, which was only detected in EST4, and $M g H o g 1 A$, a variant of $M g H o g l$ that exhibited alternative splicing in EST9. The largest variety of signaling gene expression was found in EST4 $(\mathrm{MM}+\mathrm{N})$ and EST5 $(\mathrm{MM}-\mathrm{N})$ as, out of the 11 identified signal transduction pathway orthologs, seven and eight, respectively, were found in these libraries. All libraries contained multiple signaling genes, except for EST8 (5 dpi), in which only $\mathrm{MgHog} l$ was detected.

\section{Cell wall-degrading enzymes (CWDE) are unique to in planta libraries.}

We were particularly interested in identifying genes involved in pathogenesis. These could include genes encoding enzymes involved in cell-wall degradation, as massive cell collapse occurs during pathogenesis (Kema et al. 1996). Indeed, nearly all high-abundant messengers that were unique to the in planta libraries (EST8 to EST10) had high similarity to genes encoding CWDE (Table 5). The frequency was particularly high in EST9 and EST10, which represent the onset and extension of necrotrophic growth from 10 dpi onwards.

\section{Transporter genes.}

Genes of interest in relation to secondary metabolism include ATP-binding cassette $(A B C)$ and major facilitator superfamily (MFS) transporter genes. A total of 25 contigs were identified that contained $\mathrm{ABC}$ motifs (also known as nucleotide-binding fold). ClustalX analysis (Fig. 5) of the predicted amino-acid sequence of these $M$. graminicola $\mathrm{ABC}$ protein fragments with the ABC transporter proteins identified in the genomes of $S$. cerevisiae and $N$. crassa indicated that 20 of these contigs are likely to encode $\mathrm{ABC}$ transporter genes, whereas the remaining five encode nontransporter ABC proteins. Furthermore, we identified 12 contigs encoding MFS transporters belonging to the drug/ $\mathrm{H}^{+}$antiporter family, potentially involved in the secretion of fungal toxins, fungicide sensitivity, or multidrug resistance (Sá-Correia and Tenreiro 2002).

\section{DISCUSSION}

EST sequencing has been instrumental for gene discovery, and many genes were first identified in EST libraries. This was exemplified by EST studies in Magnaporthe oryzae (Ebbole et al. 2004) and Phytophthora infestans (Randall et al. 2005), which yielded several new and unexpected gene families, such as metallothioneins and chitin synthases, respectively. The EST databases described here have already been exploited to identify new aspects of pathogenicity in M. graminicola that are related to signal transduction (Mehrabi 2006; Mehrabi and Kema 2006; Mehrabi et al. 2006a and b) and to develop mi-

Table 4. Distribution of signal transduction gene expressed sequence tags (EST) in the Mycosphaerella graminicola libraries EST1 through EST10

\begin{tabular}{|c|c|c|c|c|c|c|c|c|c|c|c|}
\hline \multirow[b]{2}{*}{ Genes } & \multicolumn{7}{|c|}{ In vitro libraries } & \multicolumn{3}{|c|}{ In planta libraries } & \multirow[b]{2}{*}{ Total } \\
\hline & EST1 & EST2 & EST3 & EST4 & EST5 & EST6 & EST7 & EST8 & EST9 & EST10 & \\
\hline \multicolumn{12}{|l|}{ MAPK genes } \\
\hline$M g F u s 3^{\mathrm{a}}$ & 1 & 4 & 5 & 2 & 1 & 0 & 1 & 0 & 0 & 0 & 14 \\
\hline $\operatorname{MgSlt} 2^{\mathrm{a}}$ & 0 & 1 & 1 & 0 & 2 & 1 & 0 & 0 & 0 & 1 & 6 \\
\hline$M g H o g 1^{\mathrm{a}}$ & 1 & 0 & 0 & 2 & 3 & 0 & 1 & 1 & 1 & 3 & 12 \\
\hline $\operatorname{MgHog} 1 A^{\mathrm{b}}$ & 0 & 0 & 0 & 0 & 0 & 0 & 0 & 0 & 1 & 0 & 1 \\
\hline \multicolumn{12}{|c|}{ MAPKK genes } \\
\hline MgSte7 & 0 & 1 & 0 & 2 & 1 & 0 & 0 & 0 & 1 & 0 & 5 \\
\hline \multicolumn{12}{|c|}{ MAPKKK genes } \\
\hline$M g S s k 2$ & 0 & 0 & 0 & 1 & 0 & 0 & 0 & 0 & 0 & 0 & 1 \\
\hline \multicolumn{12}{|l|}{ G-signaling } \\
\hline$M g G \alpha 1$ & 0 & 0 & 1 & 1 & 1 & 1 & 1 & 0 & 0 & 1 & 6 \\
\hline$M g G \alpha 2$ & 0 & 1 & 0 & 0 & 0 & 0 & 0 & 0 & 0 & 1 & 2 \\
\hline$M g G \alpha 3$ & 0 & 0 & 0 & 2 & 0 & 0 & 0 & 0 & 0 & 0 & 2 \\
\hline$M g G \beta 1$ & 0 & 2 & 0 & 0 & 4 & 0 & 3 & 0 & 1 & 0 & 10 \\
\hline \multicolumn{12}{|c|}{ cAMP signaling } \\
\hline$M g B c y 1^{\mathrm{a}}$ & 0 & 0 & 0 & 0 & 2 & 0 & 1 & 0 & 0 & 2 & 5 \\
\hline$M g T p k 2^{\mathrm{a}}$ & 1 & 2 & 1 & 1 & 2 & 0 & 1 & 0 & 0 & 2 & 10 \\
\hline
\end{tabular}

${ }^{a}$ Homologous with Hog1, Slt2, Fus3, Bcyl, and Tpk2 in Saccharomyces cerevisiae (Mehrabi et al. 2006a and b; Cousin et al. 2006; Mehrabi and Kema 2006).

b Alternative splicing of $\mathrm{MgHog} 1$.

Table 5. Abundance of cell wall-degrading enzyme mRNAs in the Mycosphaerella graminicola in planta libraries EST8 through EST10 (none of these were identified in any of the in vitro libraries

\begin{tabular}{|c|c|c|c|c|c|c|c|c|}
\hline Unigene & $E$-value & Accession no. & Species & Annotation & EST8 & EST9 & EST10 & Total \\
\hline $10 \mathrm{AK} 000735$ & $9 \mathrm{e}-80$ & EAT92052 & Phaeosphaeria nodorum & Alpha-L-arabinofuranosidase $\mathrm{a}^{\mathrm{a}}$ & 0 & 7 & 7 & 14 \\
\hline $10 \mathrm{AK} 001293$ & $4 e-68$ & XP_386621 & Fusarium graminearum & Endo-1,4-beta-xylanase ${ }^{a}$ & 0 & 4 & 8 & 12 \\
\hline $10 \mathrm{AK} 001568$ & $1 \mathrm{e}-116$ & ABN-68954 & Penicillium decumbens & Exo-cellobiohydrolase & 0 & 3 & 5 & 8 \\
\hline $10 \mathrm{AK} 001421$ & $5 e-70$ & XP_001217674 & Aspergillus terreus & Xylan 1,4-beta-xylosidase ${ }^{a}$ & 0 & 0 & 7 & 7 \\
\hline 10AK000758 & $7 e-77$ & ABG33753 & Alternaria sp. & Endo-1,4-beta-xylanase & 0 & 3 & 4 & 7 \\
\hline $10 \mathrm{AK} 000471$ & $5 e-167$ & AAT95382 & Phaeosphaeria nodorum & Beta-glucosidase & 0 & 5 & 2 & 7 \\
\hline 10AK001799 & 0.0 & AF275346 & Cladosporium fulvum & Alcohol oxidase & 1 & 3 & 1 & 5 \\
\hline $10 \mathrm{AK} 000725$ & $4 e-47$ & XP_760650 & Ustilago maydis & Alpha-galactosidase $\mathrm{a}^{\mathrm{a}}$ & 0 & 1 & 3 & 4 \\
\hline $10 \mathrm{AK} 001093$ & $3 e-60$ & XP_001258649 & Neosartorya fischeri & Acetyl xylan esterase & 1 & 0 & 3 & 4 \\
\hline $10 \mathrm{AK} 001052$ & $7 e-80$ & EAT'85854 & Phaeosphaeria nodorum & Xylan 1,4-beta-xylosidase ${ }^{a}$ & 0 & 2 & 2 & 4 \\
\hline $10 \mathrm{AK} 001121$ & $1 e-64$ & AF159252 & Cochliobolus carbonum & Pectin methylesterase & 0 & 2 & 2 & 4 \\
\hline
\end{tabular}

${ }^{a}$ Possible function derived from annotation of subsequent hits. 
crosatellite markers for population genetic studies (Goodwin et al. 2007). In addition, evidence is provided for a mycovirus in M. graminicola.

Our strategy to develop different libraries from a single isolate certainly contributed to the wide gene discovery. The data greatly add to the genomic resources available for M. graminicola and substantially extend the initial gene expression analyses of Keon and associates (2000, 2005), who analyzed 986 and 5,180 EST sequences from four libraries, resulting in 3,629 unigenes. We sequenced 27,007 EST of which $70 \%$ were estimated to be derived from full-length cDNA clones from 10 libraries of M. graminicola IPO323, which resulted in 9,190 unigenes. All libraries contributed significantly to the final set of unigenes. The overall percentage of unique sequences that was present in just one library $(65 \%$, range of the individual libraries was 28 to 46\%) is higher than in Magnaporthe oryzae (59\%; Ebbole et al. 2004), F. verticillioides (54\%; Brown et al. 2005), and P. infestans (58\%; Randall et al. 2005). The large number of high-quality EST sequences de- scribed here is indispensable for genome annotation, and recent analyses showed that up to $50 \%$ of the machine-annotated $M$. graminicola genes have EST support, which is substantially higher than the average of approximately $30 \%$ for some other fungal genomes (I. Grigoriev, unpublished data).

Efficient selection of in planta expressed fungal clones.

We were particularly interested in fungal gene expression during pathogenesis and, therefore, generated three interaction libraries (EST8 to EST10) that covered characteristic phases of the pathogenesis. The selection method described here enabled us to capture, almost exclusively, fungal genes that were expressed during early and later stages of infection. The selective hybridizations of EST8 to EST10 with the entire genomic DNA of M. graminicola identified 5, 9, and $30 \%$ of presumably fungal clones. Subsequent sequencing of these selected clones showed that the far majority was of fungal origin, which was also independently confirmed by BLAST analyses to the $M$. graminicola genome. Hence, the selection method

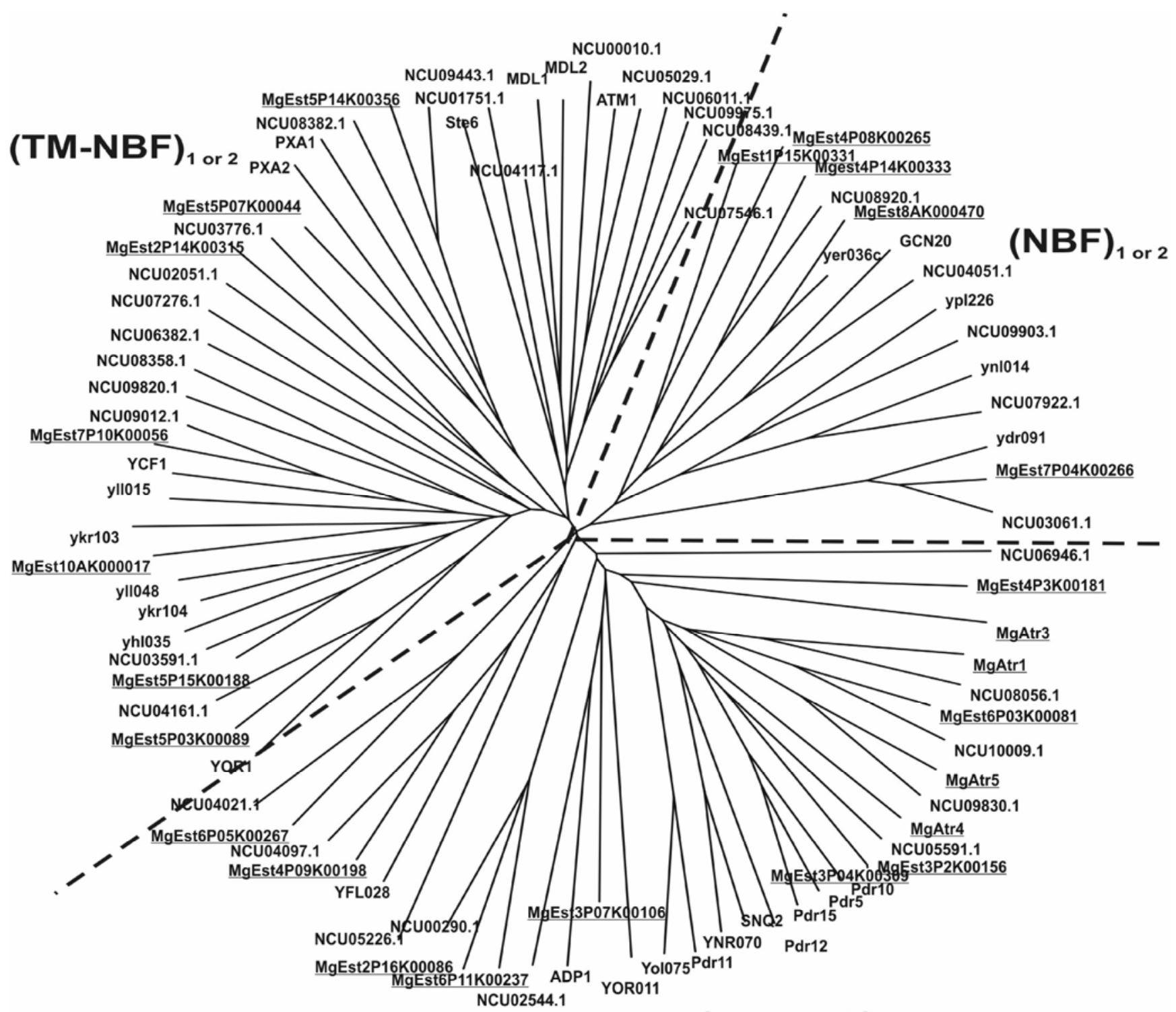

(NBF-TM) 1 or 2

Fig. 5. Phylogenetic relationship of ATP-binding cassette (ABC) proteins identified in libraries EST1 through EST10 of Mycosphaerella graminicola (underlined), Neurospora crassa (NCU numbers), and Saccharomyces cerevisiae. Relationship determined by primary sequence comparison using ClustalX (1.8). Result is presented as an unrooted neighbor-joining tree. Topology of the proteins in the different branches is indicated (NBF = nucleotide binding fold, TM $=$ transmembrane region). 
using full genome hybridization was efficient and resulted in a set of exclusively in planta-expressed genes. This procedure may also be instrumental in other pathosystems in which limited amounts of biomass of the pathogen are expected, and we successfully applied this enrichment strategy in Plasmopara viticola-grape and $F$. graminearum-wheat interactions (T. A. J. Van der Lee, C. Waalwijk, and G. H. J. Kema, unpublished results). Until now, the identification of fungal gene expression during pathogenesis from in planta libraries was cumbersome, due to the overload of expressed plant genes (Keon et al. 2005; Kim et al. 2001; Kruger et al. 2002; Randall et al. 2005). In $F$. verticillioides, BLAST analyses to the The Institute for Genomic Research maize Gene Index and comparative analyses of GYAM-induced EST and maize tissue-induced EST resulted in $2 \%$ differentially expressed sequences that potentially comprised fungal virulence factors (Brown et al. 2005), much lower than the $15 \%$ we found in this study. Randall and associates (2005) used differences in GC content as well as absence of strong hits in GenBank (BLASTN threshold E-value < -45) to predict that $18 \%$ of the EST in libraries that were constructed from infected potato and tomato plants were of $P$. infestans origin. In experiments describing the interaction between $P$. sojae and soybean, a similar approach was taken, resulting in presumed infection-specific EST (Qutob et al. 2000). Infection-specific libraries accounted for $30 \%$ of the unigenes, but the actual number of $P$. sojae sequences in these libraries is unknown. Nevertheless, these libraries showed the highest frequencies of EST encoding predicted secreted proteins that could be important for pathogenicity (Torto-Alalibo et al. 2007).

In other interaction studies involving $F$. graminearum, Magnaporthe oryzae, or M. graminicola (Keon et al. 2005; Kim et al. 2001; Kruger et al. 2002), low numbers of sequences could be assigned to the respective pathogens. Kruger and associates (2002) estimated $2 \%$ of the annotated sequences to be derived from $F$. graminearum. As they could only annotate half of the unigenes, this would result in a mere $4 \%$ recovery of fungal clones expressed in infected wheat floral tissue. In a cDNA library constructed from a compatible interaction (84 to $120 \mathrm{~h}$ after infection) between rice and Magnaporthe oryzae, $24 \%$ of the unique EST showed significant similarity with fungal genes (Kim et al. 2001).

In conclusion, genes from the pathogen expressed during the early stages of infection of the host are of great interest but difficult to obtain. Compared with the aforementioned analyses of interaction libraries our strategy i) avoided sequencing of a great number of expressed plant genes, particularly during the early phase of pathogenesis when the M. graminicola biomass is limited (Kema et al. 1996) and ii) identified a set of 932 unigenes $(15 \%$ of the total number of library-specific unigenes identified) that was exclusively expressed in planta, even during the symptomless biotrophic onset of pathogenesis. Approximately $50 \%$ of these unigenes showed no hit to fungal databases (threshold E-value <10) and may represent novel genes potentially involved in pathogenesis.

\section{CWDE are unique to in planta libraries.}

In the in planta libraries, we identified a series of genes with high similarity to genes encoding CWDE. Some CWDE are known to be essential for pathogenicity in other pathosystems, such as an endo-1,4-beta-xylanase from Botrytis cinerea, which was recently shown to be required for pathogenicity (Brito et al. 2006). Interestingly, in M. graminicola, late maximal endo-1,4-beta-xylanase production correlated well with necrosis development, whereas early $\beta$-xylosidase production correlated with lesion length in $M$. graminicola pathogenicity assays (Douaiher et al. 2007). Using our enrichment proce- dure, we identified genes that encode these proteins. A role for CWDE was proposed in some pathosystems based on expression analysis. Alpha-L-arabinofuranosidase was upregulated in F. oxysporum f. sp. dianthi infection assays (Chacón-Martínez et al. 2004) and was also expressed in F. graminearum colonizing hops cell walls (Phalip et al. 2005). Ebbole and associates (2004) used a rice cell wall-derived medium to mimic in planta conditions and identified a wide variety of CWDE, similar to our findings in the in planta libraries, suggesting that these CWDE are required for growth on cellulose and hemicellulose substrates. Although $B$. cinerea, $F$. graminearum, $F$. oxysporum f. sp. dianthi, M. graminicola, and Magnaporthe oryzae have very different lifestyles; they share a necrotrophic phase, and the expression of CWDE may reflect that stage of pathogenesis during the infection of either pathogen on their respective hosts. The occurrence of several CWDE, including multiple endo-1,4-beta-xylanases and two xylan 1,4-beta-xylosidases, suggests active cell-wall decomposition. This is in agreement with the massive cell collapse observed during the later stages of pathogenesis (Kema et al. 1996). Interestingly, hardly any CWDE were identified in EST8, which represents the biotrophic phase of pathogenesis. Although this might be due to the limited size of this library, it is more likely that our observations reflect the characteristic biotrophic and necrotrophic phases of pathogenesis of the hemibiotroph M. graminicola.

The in planta library of Keon and associates (2005) contained a high number of EST of fungal origin. However, this library was prepared from leaves at 20 to $25 \mathrm{dpi}$, when the foliar tissue is fully necrotic. At that stage $M$. graminicola is virtually exclusively involved in fructification and conidiogenesis, and the interaction between the host and the pathogen is reduced to a minimum. Library EST10 was prepared at $16 \mathrm{dpi}$, when asexual fructification has just started and interactions between plant and pathogen still play a significant role (Kema et al. 1996). Interestingly, the EST1-derived sequences (growth on an artificial support in medium prepared from apoplastic fluids extracted from wheat leaves) clustered with the in planta libraries, and apparently, this condition reflected, at least partly, the physiology of the pathogen during foliar colonization.

\section{Evidence for a mycovirus in M. graminicola.}

The most abundantly expressed gene in our database showed high similarity with a mycovirus identified in Fusarium graminearum (Chu et al. 2002). The mycoviral element was highly expressed in most libraries (EST1, EST2, and EST4 through EST6) but repressed in EST3 (mycelial growth in yeast glucose medium at $25^{\circ} \mathrm{C}$ ) and EST7 (mycelial growth at $25^{\circ} \mathrm{C}$ in yeast sucrose medium $1 \mathrm{~h}$ after administration of $10 \mathrm{ppm}$ of fungicide cyproconazole). Whether these differences reflect stressinduced virus multiplication is not evident, since application of cyproconazole (EST7) did not result in high levels of dsRNA. Moreover, fungicide stress was applied for only $1 \mathrm{~h}$ prior to RNA collection, which might have been insufficient to induce viral replication. As expected for a virus, no homology was found with the nearly finished genome sequence of $M$. graminicola isolate IPO323. Although the full genome hybridizations should have selected against this dsRNA virus, we also identified this putative mycovirus three times in the in planta libraries. Reanalysis of the digital images showed that these clones did not show hybridization with the genomic probe but slipped through the automated selection procedure due to strongly hybridizing adjacent clones. Given the high efficiency of the selection of fungal clones, this would indicate that in the original in planta libraries the mycovirus must have been present in very high numbers. Chu and associates (2002) demonstrated that the mycovirus posed pronounced effects on the morphology of $F$. graminearum, including reduced mycelial growth, decreased 
production of mycotoxins, and reduced virulence. Whether the mycovirus reported here exerts similar effects on $M$. graminicola will be subject to future research.

\section{Genes involved in signal transduction and transport.}

The coverage of genes encoding enzymes belonging to various signal transduction pathways was remarkable. We found a total of 74 transcripts with significant hits to earlier described genes involved in four MAPK pathways and the cAMP-dependent pathway in $S$. cerevisiae (Xu 2000). In several dimorphic pathogens, such as Ustilago maydis and Candida albicans, the switch from budding to filamentous growth is essential for pathogenicity. M. graminicola is also a dimorphic pathogen with a yeast-like blastic conidiogenesis (typical for EST2) and filamentous growth (typical for EST3 as well as in planta growth represented by EST8 to EST10). We recently demonstrated that filamentous growth of $M$. graminicola is required to enter the host through the natural openings of the leaves, by the functional analysis of $\mathrm{MgHog} 1$ (Mehrabi et al. 2006b), which is part of the high osmolarity pathway in $S$. cerevisiae. During the course of pathogenesis, the role of offensive and defensive fungal and plant-derived compounds, such as fungal toxins and phytoalexins has been suggested (Kema et al. 1996; Keon et al. 2007). We demonstrated that disruption of MgSlt2, the homolog of slt2 of S. cerevisiae, in $M$. graminicola significantly affected invasive growth during pathogenesis, due to an increased sensitivity to plant-derived compounds (Mehrabi et al. 2006a). In summary, the current EST data set has resulted in the identification of 11 signal transduction genes that were validated for pathogenicity (Mehrabi 2006), demonstrating the value of these EST data.

Mining the EST libraries for ABC transporters resulted in 25 genes encoding proteins with strong resemblance to proteins with $\mathrm{ABC}$ motifs. Based on the homology to other fungal $\mathrm{ABC}$ proteins, we concluded that 20 are true $\mathrm{ABC}$ transporters, while the remaining five are nontransporter $\mathrm{ABC}$ proteins. Four ABC transporters were previously characterized (Zwiers et al. 2003), indicating that 16 new $A B C$ transporters were identified. In several plant-pathogenic fungi such as $B$. cinerea, F. culmorum, Magnaporthe oryzae, and M. graminicola ABC transporters have been ascribed a role in pathogenesis (Schoonbeek et al. 2001; Skov et al. 2004; Stergiopoulos et al. 2003; Urban et al. 1999). Four ABC transporters were expressed in planta, including the previously described $M g A t r 3$ and MgAtr4. The former was found only once in EST9, whereas the latter, which was previously shown to be a virulence factor (Stergiopoulos et al. 2003), was expressed in multiple libraries (EST1, EST3, EST7, and EST10). This is interesting, since in previous expression studies using Northern hybridization, no expression of MgAtr3 could be detected (Stergiopoulos et al. 2002). The two other ABC transporters that were found in the in planta EST libraries appear to be members of the multidrug resistance-related protein family, a class of $\mathrm{ABC}$ transporters involved in the transport of conjugated compounds and involved in metal resistance. In addition to the ABC transporters, we identified 12 MFS transporters. Functional analysis of one of these, $M g M f_{s} 1$, showed that it is involved in sensitivity to strobilurine fungicides as well as the mycotoxin cercosporin (Roohparvar et al. 2007).

\section{Similarity of predicted proteins with the proteome of other filamentous fungi.}

BLASTX analysis of all 9,190 unigenes with the predicted proteomes of Stagonospora nodorum, F. graminearum, Magnaporthe oryzae, N. crassa, and S. cerevisiae showed that, even with the closest related species Stagonospora nodorum, only $57 \%$ of the translated EST sequences had high similarity
(E-value <-10). Apparently, many of the genes found in $M$. graminicola have diverged considerably from their orthologs in Stagonospora nodorum. Alternatively, many genes are unique and have no ortholog in Stagonospora nodorum. The percentages of the translated EST sequences with high similarity $($ E-value $<-10)$ dropped slightly when comparing the unigenes of $M$. graminicola with the predicted proteome of $F$. graminearum (51\%), Magnaporthe oryzae (49\%), N. crassa (48\%), and sharply when compared with the proteome of $S$. cerevisiae (27\%). Stagonospora nodorum and M. graminicola both belong to the class Dothideomycetes in the orders Pleosporales and Capnodiales (Schoch et al. 2006), and cause glume blotch and leaf blotch in wheat, respectively. However, Stagonospora nodorum also infects the nodes and foliage and was reported to be seed transmitted (Shah et al. 2000; Solomon et al. 2006). Hence, comparative genomics using subtractive approaches of foliar and floral data sets from $M$. graminicola and either Stagonospora nodorum or F. graminearum, respectively, might reveal clues on genes that are specifically involved in infection of the cereal inflorescence. As these fungi have important differences in lifestyle, such as hemibiotrophy vs. necrotrophy, and infection of stem, floral, or foliar tissues, this will provide unparalleled opportunities to study aspects of adaptation of these important plant pathogens.

\section{MATERIALS AND METHODS}

\section{Growth conditions of $M$. graminicola to produce 10 EST libraries.}

Ten libraries, seven in vitro and three in planta libraries, were made using the Dutch $M$. graminicola field strain IPO323 (Kema and Van Silfhout 1997). Three in vitro libraries (EST1 to EST3) were generated from conditions that we considered typical for M. graminicola and were started with conidia harvested from yeast-glucose broth (YGB; $1 \%$ yeast extract, $3 \%$ glucose; $0.5 \mathrm{ml}$ of spore suspension $\left[1 \times 10^{7}\right.$ spores per $\mathrm{ml}$ ] in $150 \mathrm{ml}$ of fresh medium). Cultures for the construction of libraries EST4 and EST5 were started with conidia harvested from minimal medium (synthetischer nährstoffarmer broth [SNB]; Nirenberg 1976), and the culture for EST7 was started from yeast-sucrose broth (1\% yeast extract, $1 \%$ sucrose, $50 \mu \mathrm{g}$ of streptomycin sulphate per milliliter). The first library mimics the intercellular growth of $M$. graminicola during the biotrophic phase in the host. To this end, approximately $100 \mathrm{ml}$ of apoplastic fluid, collected by vacuum infiltration of 10-day-old primary leaves of the wheat cv. Obelisk (De Wit and Spikman 1982), was supplemented with a plastic kitchen sponge (EST1). This vinyl sponge was submerged in apoplastic fluid that was subsequently inoculated with a yeast-glucose suspension of $M$. graminicola isolate IPO323 and shaken for $73 \mathrm{~h}$ at $16^{\circ} \mathrm{C}$ and $120 \mathrm{rpm}$.

Two libraries were constructed to represent the dimorphic switch between blastic conidiogenesis or yeast-like growth at $16^{\circ} \mathrm{C}$ (EST2) and filamentous growth at $25^{\circ} \mathrm{C}$ (EST3), using YGB and harvesting conidia at log phase at $100 \mathrm{~h}$. Two libraries were generated from conidia harvested from 60-h logphase cultures in SNB with (EST4) and without (EST5) $\mathrm{KNO}_{3}$ as sole $\mathrm{N}$ source $\left(16^{\circ} \mathrm{C}\right)$ to simulate potential nutrient depletion during the first intercellular phase of pathogenesis. This might be associated with the typical and rapid apical leaf necrosis during that phase of the interaction as a result of the decreasing directly available nitrogen in diseased cereal leaves (Van den Berg et al. 2007). Water agar provides excellent conditions for spore germination and filamentous growth that is highly similar to the initial phase on the plant surface prior to stomatal penetration (Kema et al. 1996; Mehrabi et al. 2006b). We therefore constructed a library from mRNA harvested from 
a spore suspension grown for $36 \mathrm{~h}$ on water agar covered with sterile cellophane $\left(20^{\circ} \mathrm{C}\right.$, EST6). Finally, we constructed one library from RNA isolated from 3-day-old liquid $M$. graminicola cultures with a filamentous phenotype $\left(25^{\circ} \mathrm{C}\right)$ that were exposed for $1 \mathrm{~h}$ to $10 \mathrm{ppm}$ of the azole fungicide cyproconazole, which is commonly used to control septoria tritici blotch in the field (EST7) (Zwiers and De Waard 2000). All broth cultures were maintained in an orbital incubated shaker (Innova 4430, New Brunswick Scientific, Nijmegen, The Netherlands) adjusted at $120 \mathrm{rpm}$, and conidia or mycelium were collected by centrifugation and were washed with water before RNA extraction. Three in planta libraries were constructed from representative phases of pathogenesis (Kema et al. 1996). Ten-dayold seedlings of cv. Obelisk were inoculated until run-off with a spore suspension derived from YGB cultures maintained at $18^{\circ} \mathrm{C}$ in an orbital incubated shaker for 5 days at $120 \mathrm{rpm}$, which was adjusted at $1 \times 10^{7}$ spores per milliliter and was supplemented with $0.15 \%$ Tween 20 as a surfactant. Inoculated plants were placed in transparent polyethylene boxes and were incubated at $20^{\circ} \mathrm{C}$ in the dark for $48 \mathrm{~h}$, and subsequently, were incubated at $16 \mathrm{~h}$ light $\left(166 \mu \mathrm{E} \mathrm{s}^{-1} \mathrm{~m}^{-2}\right)$ and $8 \mathrm{~h}$ darkness per day. Inoculated leaves were harvested at 5, 10, and 16 dpi to construct libraries EST8 to EST10.

\section{RNA isolation, cDNA generation, cloning, and selection.}

Total RNA was isolated, using the RNeasy plant mini kit (Qiagen, Hilden, Germany) according to the instructions of the manufacturer, and Poly $\mathrm{A}^{+}$RNA was isolated using the Oligotex kit from Qiagen. The SuperScript plasmid system for cDNA synthesis and plasmid cloning kit (Invitrogen Life Technologies, Groningen, The Netherlands) were used according to instructions to synthesize cDNAs that were subsequently directionally cloned into vector pSPORT 1 . Ligated cDNAs were introduced into Escherichia coli DH10B ELECTROMAXcompetent cells by electroporation. Fungal clones were selected from the in planta libraries EST8 to EST10 sequences by hybridizing high-density filters containing 1,536 colonies $(4 \times$ 384 ), which were spotted in duplicate across an empty central spot, resulting in 3,072 clones per filter. After overnight growth, colonies were lysed and filters were hybridized with a ${ }^{33} \mathrm{P}$-dATP random prime total genomic DNA of $M$. graminicola IPO323. The DNA was sheared to 200- to 1,000-bp fragments by sonification and was labeled, using the random prime labeling kit (BRL, Gaithersburg, MD, U.S.A.) according to the manufacturer's protocol, with the exception that $10 \mu \mathrm{l}$ of ${ }^{33} \mathrm{P}$ dATP was used for $100 \mathrm{ng}$ DNA. Filters were scanned using a phospho-imager (BAS, Fuiji, Tokyo), and images were imported into the image analysis software program AIS 4.0 (Imaging Research Inc., St. Catharines, Canada), using a $3 \times 3$ grid and local background subtraction (middle spot). Clones were selected if the average of the two duplicate spots minus the difference of the two spots was higher than two times the background, using macros written in Microsoft Excel.

\section{DNA sequencing, assembly, quality control, and analyses.}

Inserts were amplified by polymerase chain reaction using primers T7 (5'-TAATACGACTCACTATAGGG-3') and SP6 (5'-TATTTAGGTGACACTATAG-3') and, subsequently, were sequenced with $\mathrm{T} 7 \mathrm{~s}$ on an ABI-prism 3700 capillary automated sequencer using the BigDye terminator reaction mix (Applied Biosystems, Nieuwerkerk, The Netherlands). Base calling of reads was performed with PHRED, after sequences were trimmed for quality (cutoff: Q20; Ewing et al. 1998), vector sequences (pSPORT1), and poly-A tails, using PREGAP4. Subsequently, sequences were assembled into unigenes using the GAP4 assembler (settings: 20-nt overlap, 90\% similarity, maximum of 15 pads).
Quality controls were performed using reference RNA (tetracycline-resistance gene) coming with the Oligotex Qiagen kit and using a test set of library EST3 to determine the number of reads and the average read and contig lengths as well as the total contig length. We also determined the average insert length in EST2 through EST7, and the percentage of fulllength clones, based on the abundantly expressed elongation factor genes $E F-1 \alpha$ and EF2. All contigs from EST1 through EST10 as well as the total assembly were analyzed using BLASTn and BLASTx (e-5 threshold on the Fusarium graminearum genome and mitochondrion [version 3, BROAD], the Neurospora crassa genome [version 7, BROAD] and mitochondrion [version 3, BROAD], the Stagonospora nodorum genome [version 1, BROAD] and mitochondrion [accession gi|156494363|ref|NC_009746.1, GenBank], the Magnaporthe grisea genome and mitochondrion [version 5, BROAD], and the Saccharomyces cerevisiae genome [accession NC_001133 tm NC_001148, GenBank] and mitochondrion [accession gi|6226515|ref|NC_001224.1, GenBank]) (Altschul et al. 1990, 1997). From these analyses, we determined that EST1 and EST6 contained two different EF1 $\alpha$ and EF2 contigs. One of each had high hits with Aureobasidium, suggesting potential contamination of the material that was used to construct these libraries. Therefore, we blasted these EST libraries to the $M$. graminicola genome sequence (version Mgram041607.main_genome.fasta downloaded from the Joint Genome Institute website, 23 scaffolds and mitochondrion, accession gi|155964387|gb|EU090238.1, GenBank; Blast of library multifastas against genome and mitochondrion-only best hits, no low-complexity filtering, threshold e-10; hit identity represents the best scoring HSP) to filter the data from potential contaminants and to verify the aforementioned selection process used in the analyses of EST8 through EST10 (for hits with low-identity, unigenes with a best HSP identity $<98 \%$ were rejected, hits on mitochondrion were accepted, unigenes with 'no hits found' but present in libraries EST2 to EST5 and EST7 were also accepted). We used the Genome Content Comparison database that was developed (Van Oers et al. 2005) to access and compare all publicly available databases containing relevant microbial sequences for final gene annotation.

Finally, we identified a set of unigenes ( $n=825$, based on $56 \%$ of the total number of EST reads) that was present in a minimum of four and maximum of nine EST libraries, and we subsequently scored their presence in each individual EST library, to determine whether the generation of multiple libraries from different in vitro and in planta conditions substantially contributed to the desired maximum diversity in gene expression. The data were analyzed using TREECON for Windows version $1.3 \mathrm{~b}$, with a distance estimation according to Nei and Li (1979), a bootstrap analysis with 1,000 runs, and considering libraries as individuals and the unigenes as markers (van Peer and de Wachter 1994). The tree topology was calculated using neighbor-joining (also with a bootstrap analysis using 1,000 runs) and was rooted using EST7 in the single sequence mode followed, by another bootstrap analysis with 1,000 runs.

\section{ACKNOWLEDGMENTS}

We gratefully acknowledge the financial support of Syngenta and its predecessor Zeneca. We are thankful for permission of the United States Department of Energy-Joint Genome Institute to use the latest nonpublic release of the $M$. graminicola IPO323 genome sequence for BLAST analyses. We thank the Greenomics colleagues and the Dutch Mycosphaerella Group for discussions. G. H. J. Kema received an Organization for Economic and Cooperation Development fellowship to the United States Department of Agriculture-Agricultural Research Service at Purdue University, West Lafayette, IN, U.S.A. 


\section{LITERATURE CITED}

Altschul, S. F., Gish, W., Miller, W., Myers, E. W., and Lipman, D. J. 1990. Basic local alignment search tool. J. Mol. Biol. 215:403-410.

Altschul, S. F., Madden, T. L., Schaeffer, A. A., Zhang, J., Zhang, Z., Miller, W., and Lipman, D. J. 1997. Gapped BLAST and PSI-BLAST: A new generation of protein database search programs. Nucleic Acids Res. 25:3389-3402.

Bearchell, S. J., Fraaije, B. A., Shaw, M. W., and Fitt, B. D. L., 2005. Wheat archive links long-term fungal pathogen population dynamics to air pollution. Proc. Natl. Acad. Sci. U.S.A. 102:5438-5442.

Brito, N., Espino, J. J., and González, C. 2006. The endo- $\beta-1,4-x y l a n a s e$ Xyn11A is required for virulence in Botrytis cinerea. Mol. PlantMicrobe Interact. 19:25-32.

Brown, D. W., Cheung, F., Proctor, R. H., Butchko, R. A. E., Zheng, L., Lee, Y., Utterback, T., Smith, S., Feldblyum, T., Glenn, A. E., Plattner, R. D., Kendra, D. F., Town, C. D., and Whitelaw, C. A. 2005. Comparative analysis of 87,000 expressed sequence tags from the fumonisin-producing fungus Fusarium verticilliödes. Fungal Genet. Biol. 42:848-861.

Chacón-Martínez, C. A., Anzola, J. M., Rojas, A., Hernández, F., Junca, H., Ocampo, W., and Del Portillo, P. 2004. Identification and characterization of the a-L arabinofuranosidase B of Fusarium oxysporum $\mathrm{f}$. sp. dianthi. Physiol. Mol. Plant Pathol. 64:201-208.

Chu, J. M., Jeon, J. J., Yea, S. J., Kim, Y. H., Yun, S. H., Lee, Y. W., and Kim, K. H. 2002. Double-stranded RNA mycovirus from Fusarium graminearum. Appl. Environ. Microbiol. 68:2529-2534.

Cousin, A., Mehrabi, R., Guilleroux, M., Dufresne, M., Van der Lee, T. A. J., Waalwijk, C., Langin, T., and Kema, G. H. J., 2006. The MAP kinase-encoding gene $M g F u s 3$ of the non-appressorium phytopathogen Mycosphaerella graminicola is required for penetration and in vitro pycnidia formation. Mol. Plant Pathol. 7:269-278.

Dean, R. A., Talbot, N. J., Ebbole, D. J., Farman, M. F., Mitchell, T. K., Orbach, M. J., Thon, M., Kulkarni, R., Xu, J.-R., Pan, H., Read, N. D., Lee, Y-H., Carbone, I., Brown, D., Oh, Y. Y., Donofrio, N., Jeong, J. S., Soanes, D. M., Djonovic, S., Kolomiets, E., Rehmeyer, C., Li, W., Harding, M., Kim, S., Lebrun, M.-H., Bohnert, H., Coughlan. S., Butler, J., Calvo, S., Ma, L.-J., Nicol, R., Purcell, S., Nusbaum, C., Galagan, J. E., and Birren, B. W. 2005. The genome sequence of the rice blast fungus Magnaporthe grisea. Nature 434:980-986.

De Wit, P. J. G. M., and Spikman, G. 1982. Evidence for the occurrence of race and cultivar-specific elicitors of necrosis in intercellular fluids of compatible interactions of Cladosporium fulvum and tomato. Physiol. Plant Pathol. 21:1-11.

Douaiher, M.-N., Nowak, E., Durand, R., Halama, P., and Reignault, P. 2007. Correlative analysis of Mycosphaerella graminicola pathogenicity and cell wall-degrading enzymes produced in vitro: The importance of xylanase and polygalacturonase. Plant Pathol. 56:79-86.

Duncan, K. E., and Howard, R. J. 2000. Cytological analysis of wheat infection by the leaf blotch pathogen, Mycosphaerella graminicola. Mycol. Res. 104:1074-1082.

Ebbole, D. J., Jin, Y., Thon, M., Pan, H., Bhattarai, E., Thomas, T., and Dean, R. 2004. Gene discovery and gene expression in the rice blast fungus, Magnaporthe grisea: Analysis of expressed sequence tags. Mol. Plant-Microbe Interact. 17:1337-1347.

Ewing, B., Hillier, L., Wendl, M. C., and Green, P. 1998. Base-calling of automated sequencer traces using phred. I. Accuracy assessment. Genome Res. 8:175-185.

Farr, D. F., Bills, G. F., Chamuris, G. P., and Rossman, A. Y. 1995. Fungi on Plants and Plant Products in the United States. American Phytopathological Press, St. Paul, MN, U.S.A.

Fraaije, B. A., Cools, H. J, Kim, S.-H., Motteram, J., Clark, W. S., and Lucas, J. A. 2007. A novel substitution I381V in the sterol $14 \alpha$-demethylase (CYP51) of Mycosphaerella graminicola is differentially selected by azole fungicides. Mol. Plant Pathol. 8:245-254

Galagan, J. E., Calvo, S. E., Borkovich, K. A., Selker, E. U., Read, N. D., Jaffe, D., FitzHugh, W., Ma, L.-J., Smirnov, S., Purcell, S., Rehman, B., Elkins, T., Engels, R., Wang, S., Nielsen, C. B., Butler, J., Endrizzi, M., Qui, D., Ianakiev, P., Bell-Pedersen, D., Nelson, M. A., WernerWashburne, M., Selitrennikoff, C. P., Kinsey, J. A., Braun, E. L., Zelter, A., Schulte, U., Kothe, G. O., Jedd, G., Mewes, W., Staben, C., Marcotte, E., Greenberg, D., Roy, A., Foley, K., Naylor, J., Stange-Thomann, N., Barrett, R., Gnerre, S., Kamal, M., Kamvysselis, M., Mauceli, M., Bielke, C., Rudd, S., Frishman, D., Krystofova, S., Rasmussen, C., Metzenberg, R. L., Perkins, D. D., Kroken, S., Cogoni, C., Macino, G., Catcheside, D., Li, W., Pratt, R. J., Osmani, S. A., DeSouza, C. P. C., Glass, L., Orbach, M. J., Berglund, J. A., Voelker, R., Yarden, O., Plamann, M., Seiler, S., Dunlap, J., Radford, A., Aramayo, R., Natvig, D. O., Alex, L. A., Mannhaupt, G., Ebbole, D. J., Freitag, M., Paulsen, I., Sachs, M. S., Lander, E. S., Nusbaum, C., and Birren, B. 2003. The genome sequence of the filamentous fungus Neurospora crassa. Nature 422:859-868.
Goodwin, S. B. 2007. Back to basics and beyond: Increasing the level of resistance to septoria tritici blotch in wheat. Australas. Plant Pathol. 36:532-538.

Goodwin, S. B., Waalwijk, C., and Kema, G. H. J. 2004. Genetics and genomics of Mycosphaerella graminicola, a model for the Dothideales. Pages 315-330 in: Applied Mycology \& Biotechnology. Volume 4. Fungal Genomics. Elsevier Science B, New York.

Goodwin, S. B., Van der Lee, T. A. J., Cavaletto, J. R., Te Lintel Hekkert, B., and Kema, G. H. J. 2007. Database mining and genetic mapping of highly polymorphic microsatellites in Mycosphaerella graminicola. Fungal Genet. Biol. 44:398-414.

Kema, G. H. J., and Van Silfhout, C. H., 1997. Genetic variation for virulence and resistance in the wheat-Mycosphaerella graminicola pathosystem. III. Comparative seedling and adult plant experiments. Phytopathology 87:266-272.

Kema, G. H. J., Yu, D. Z., Rijkenberg, F. H. J., Shaw, M. W., and Baayen, R. P. 1996. Histology of the pathogenesis of Mycosphaerella graminicola in wheat. Phytopathology 86:777-786.

Kema, G. H. J., Verstappen, E. C. P., and Waalwijk, C. 2000. Avirulence in the wheat septoria tritici leaf blotch fungus Mycosphaerella graminicola is controlled by a single locus. Mol. Plant-Microbe Interact. 13:1375-1379.

Kema, G. H. J., Goodwin, S. B., Hamza, S., Verstappen, E. C. P., Cavaletto, J. R., Van der Lee, T. A. J., Hagenaar-de Weerdt, M., Bonants, P. J. M., and Waalwijk, C. 2002. A combined AFLP and RAPD genetic linkage map of Mycosphaerella graminicola, the septoria tritici leaf blotch pathogen of wheat. Genetics 161:1497-1505.

Keon, J., Bailey, A., and Hargreaves, J. 2000. A group of expressed cDNA sequences from the wheat fungal leaf blotch pathogen, Mycosphaerella graminicola (Septoria tritici). Fungal Genet. Biol. 29:118-133.

Keon, J., Antoniw, J., Rudd, J., Skinner, W., Hargreaves, J., and Hammond-Kosack, K. 2005. Analysis of expressed sequence tags from the wheat leaf blotch pathogen Mycosphaerella graminicola (anamorph Septoria tritici). Fungal Genet. Biol. 42:376-389.

Keon, J., Antoniw, J., Carzaniga, R., Deller, S., Ward, J. L., Baker, J. M. Beale, M. H., Hammond-Kosack, K., and Rudd, J. J. 2007. Transcriptional adaptation of Mycosphaerella graminicola to programmed cell death (PCD) of its susceptible wheat host. Mol. Plant-Microbe Interact. 20:178-193.

Kim, S., Ahn, I.-P., Lee, and Y.-H. 2001. Analysis of genes expressed during rice-Magnaporthe grisea interactions. Mol. Plant-Microbe Interact. 14:1340-1346.

Kruger, W. M., Pritsch, C., Chao, S., and Muehlbauer, G. J., 2002. Functional and comparative bioinformatic analysis of expressed genes from wheat spikes infected with Fusarium graminearum. Mol. PlantMicrobe Interact. 15:445-455.

Mehrabi, R. 2006. Signaling pathways involved in pathogenicity and development of the fungal wheat pathogen Mycosphaerella graminicola. Ph.D. thesis. Wageningen University, The Netherlands.

Mehrabi, R., and Kema, G. H. J. 2006. Protein kinase A subunits of the ascomycete pathogen Mycosphaerella graminicola regulate asexual fructification, filamentation, melanization and osmosensing. Mol. Plant Pathol. 7:565-577.

Mehrabi, R., Van der Lee, T. A. J., Waalwijk, C., and Kema, G. H. J. 2006a. MgSlt2, a cellular integrity MAP kinase of the fungal wheat pathogen Mycosphaerella graminicola, is dispensable for penetration but essential for invasive growth. Mol. Plant-Microbe Interact. 19:389398

Mehrabi, R., Zwiers, L. H., De Waard, M., and Kema, G. H. J. 2006b. $\mathrm{MgHog} 1$ regulates dimorphism and pathogenicity in the fungal wheat pathogen Mycosphaerella graminicola. Mol. Plant-Microbe Interact. 19:1262-1269.

Mewes, H. W., Frishmann, D., Guldener, U., Mannhaupt, G., Mayer, K. Mokresj, M., Morgenstern, B., Munsterkotter, M., Rudd, S., and Weil, B. 2002. MIPS: A database for genomes and protein sequences. Nucleic Acids Res. 30:31-34.

Nei, M., and Li, W.-H. 1979. Mathematical model for studying genetic variation in terms of restriction endonucleases. Proc. Natl. Acad. Sci. U.S.A. 76:5269-5273.

Nirenberg, H. I. 1976. Untersuchungen über die morphologische und biologische Differenzierung in der Fusarium-Sektion Liseola. Mitt. Biol. Bundesanst. Land Forstwitsch. Berlin-Dahlem 169:1-117.

Phalip, V., Delalande, F., Carapito, C., Goubet, F., Hatsch, D., LeizeWagner, E., Dupree, P., Van Dorsselaer, A., and Jeltsch, J.-M. 2005. Diversity of the exoproteome of Fusarium graminearum grown on plant cell wall. Curr. Genet. 48:366-379.

Qutob, D., Hraber, P. T., Sobral, B. W., and Gijzen, M. 2000. Comparative analysis of expressed sequences in Phytophthora sojae. Plant Physiol. 123:243-254.

Randall, T. A., Dwyer, R. A., Huitema, E., Beyer, K., Cvitanich, C., Kelkar, 
H., Ah Fong, A. M. V., Gates, K., Roberts, S., Yatzkan, E., Gaffney, T. Law, M., Testa, A., Torto-Alalibo, T., Zhang, M., Zheng, L., Mueller, E., Windass, J., Binder, A., Birch, P. R. J., Gisi, U., Govers, F., Gow, N. A., Mauch, F., Van West, P., Waugh, M. E., Yu, J., Boller, T., Kamoun, S., Lam, S. T., and Judelson, H. S. 2005. Large-scale gene discovery in the oomycete Phytophthora infestans reveals likely components of phytopathogenicity shared with true fungi. Mol. Plant-Microbe Interact. 18:229-243.

Roohparvar, R., De Waard, M. A., Kema, G. H. J., and Zwiers, L.-H. 2007. $M g M f s 1$, a major facilitator superfamily transporter from the fungal wheat pathogen Mycosphaerella graminicola, is a strong protectant against natural toxic compounds and fungicides. Fungal Genet. Biol. 44:378-388

Sá-Correia, I., and Tenreiro, S. 2002. The multidrug resistance transporters of the major facilitator superfamily, 6 years after disclosure of Saccharomyces cerevisiae genome sequence. J. Biotechnol. 98:215-226.

Schoch, C. L., Shoemaker, R. A., Seifert, K. A., Hambleton, S., Spatafora, J. W., and Crous, P. W., 2006. A multigene phylogeny of the Dothideomycetes using four nuclear loci. Mycologia 98:1041-1052.

Schoonbeek, H., Del Sorbo, G., and De Waard, M. A. 2001. The ABC transporter BcatrB affects the sensitivity of Botrytis cinerea to the phytoalexin resveratrol and the fungicide fenpiclonil. Mol. Plant-Microbe Interact. 14:562-571.

Shah, D. A., Bergstrom, G. C., and Sorrells, M. E., 2000. Differential seed infection of wheat cultivars by Stagonospora nodorum. Plant Dis. 84:749-752.

Shetty, N. P., Mehrabi, R., Lütken, H., Haldrup, A., Kema, G. H. J., Collinge, D. B., and Jørgensen, H. J. L. 2007. Role of hydrogen peroxide during the interaction between the hemibiotrophic fungal pathogen Septoria tritici and wheat. New Phytol. 174:637-647.

Sierotzki, H., Pavic, L., Hugelshofer, U., Stanger, C., Cleere, S., Windass, J., and Gisi, U. 2005. Dynamics of Mycosphaerella graminicola populations in response to selection by different fungicides. Pages 89-101 in: Modern Fungicides and Antifungal Compounds II. H. Lyr, P. E. Russell, H. W. Dehne, U. Gisi, and K. H. Kuck, eds. 14th International Reinhardsbrunn Symposium, AgroConcept, Bonn.

Skov, J., Lemmens, M., and Giese, H. 2004. Role of a Fusarium culmorum $\mathrm{ABC}$ transporter $(F c A B C 1)$ during infection of wheat and barley. Physiol. Mol. Plant Pathol. 64:245-254.

Solomon, P. S., Lowe, R. G. T., Tan, K.-C., Waters, O. D. C., and Oliver, R. P. 2006. Stagonospora nodorum cause of stagonospora nodorum blotch of wheat. Mol. Plant Pathol. 7:147-156.

Stergiopoulos, I., Gielkens, M. M. C., Goodall, S. D., Venema, K., and De Waard, M. A. 2002. Molecular cloning and characterisation of three new $\mathrm{ABC}$ transporter encoding genes from the wheat pathogen $M y$ cosphaerella graminicola. Gene 289:141-149.
Stergiopoulos, I., Zwiers, L.-H., and De Waard, M. A. 2003. The ABC transporter MgAtr4 is a virulence factor of Mycosphaerella graminicola that affects colonization of substomatal cavities in wheat leaves. Mol. Plant-Microbe Interact. 16:689-698.

Torto-Alalibo, T. A., Tripathy, S., Smith, B. M., Arredondo, F. D., Zhou, L., Li, H., Chibucos, M. C., Qutob, D., Gijzen, M., Mao, C., Sobral, B. W. S., Waugh, M. E., Mitchell, T. K., Dean, R. A., and Tyler, B. M. 2007. Expressed sequence tags from Phytophthora sojae reveal genes specific to development and infection. Mol. Plant-Microbe Interact. 20:781-793.

Urban, M., Bhargava, T., and Hamer, J. E. 1999. An ATP-driven efflux pump is a novel pathogenicity factor in rice blast disease. EMBO (Eur. Mol. Biol. Organ.) J 18:512-521.

Van de Peer, Y., and De Wachter, R. 1994. TREECON for Windows: A software package for the construction and drawing of evolutionary trees for the Microsoft Windows environment. Comput Appl. Biosci 10:569570 .

Van den Berg, F., Robert, C., Shaw, M. W., and Van den Bosch, F. 2007. Apical leaf necrosis and leaf nitrogen dynamics in diseased leaves: A model study. Plant Pathol. 56:424-436.

Van Oers, M. M., Abma-Henkens, M. H. C., Herniou, E. A., de Groot, J. C. W., Peters, S., and Vlak, J. M., 2005. Genome sequence of Chrysodeixis chalcites nucleopolyhedrovirus, a baculovirus with two DNA photolyase genes. J. Gen. Virol. 86:2069-2080.

$\mathrm{Xu}$, J. R. 2000. MAP kinases in fungal pathogens. Fungal Genet. Biol. 31:137-152.

Zhan, J., Pettway, R. E., and McDonald, B. A. 2003. The global genetic structure of the wheat pathogen Mycosphaerella graminicola is characterized by high nuclear diversity, low mitochondrial diversity, regular recombination, and gene flow. Fungal Genet. Biol. 38:286-297.

Zwiers, L.-H., Stergiopoulos, I., Gielkens, M. M. C., Goodall, S. D., and De Waard, M. A., 2003. ABC transporters of the wheat pathogen $M y$ cosphaerella graminicola function as protectants against biotic and xenobiotic toxic compounds. Mol. Gen. Genet. 269:499-507.

Zwiers, L.-H., and De Waard, M. A., 2000. Characterization of the ABC transporter genes MgAtrl and MgAtr2 from the wheat pathogen $M y-$ cosphaerella graminicola. Fungal Genet. Biol. 30:115-125.

\section{AUTHOR-RECOMMENDED INTERNET RESOURCES}

United States Department of Energy-Joint Genome Institute (DOE-JGI) Mycosphaerella genome portal: genome.jgi-psf.org/Mycgr1/Mycgr1.home.html

DOE-JGI motivation to sequence Mycosphaerella graminicola: www.jgi.doe.gov/sequencing/why/3149.html 